\title{
Carbon Nanotubes: Exploring Intrinsic Medicinal Activities and Biomedical Applications
}

\author{
Surya Prakash Gautam ${ }^{1 *}$, Bhupinder Kaur ${ }^{2}$ and Tapsya Gautam ${ }^{1}$ \\ ${ }^{1}$ Department of Pharmaceutics, CT Institute of Pharmaceutical Sciences, India \\ ${ }^{2}$ Baba Isher Singh College of Pharmacy, India
}

*Corresponding author: Surya Prakash Gautam, Department of Pharmaceutics, CT Institute of Pharmaceutical Sciences, India

\section{Introduction}

Carbon Nano materials the king of nonmaterial's have fascinating nanofamily including buckyballs or buckminsterfullerenes [1], multiwalled carbon nanotubes [2], the single-walled carbon naotubes(SWCNTs) [3], Carbon Nanohorns(CNHs), Carbon nanocones, Carbon nanofibers (CNFs), carbon nanothread, Buckypaper, carbon dots, nanodimons, nanoonions, nanorods, nanoribbons. Also called as powerful particles, CNTs (carbon nanotubes) has thus bloomed over the past decade [4,5]. Increasing evidence has shown that certain CNT properties such as nano-sized dimension, high surface energy, and large reactive surface area are directly correlated to their biological activities [6,7]. Great property of loading various biomolecules, diagnostic and therapeutic moieties resulting in diversified biomedical applications of CNTs (Figure 1).

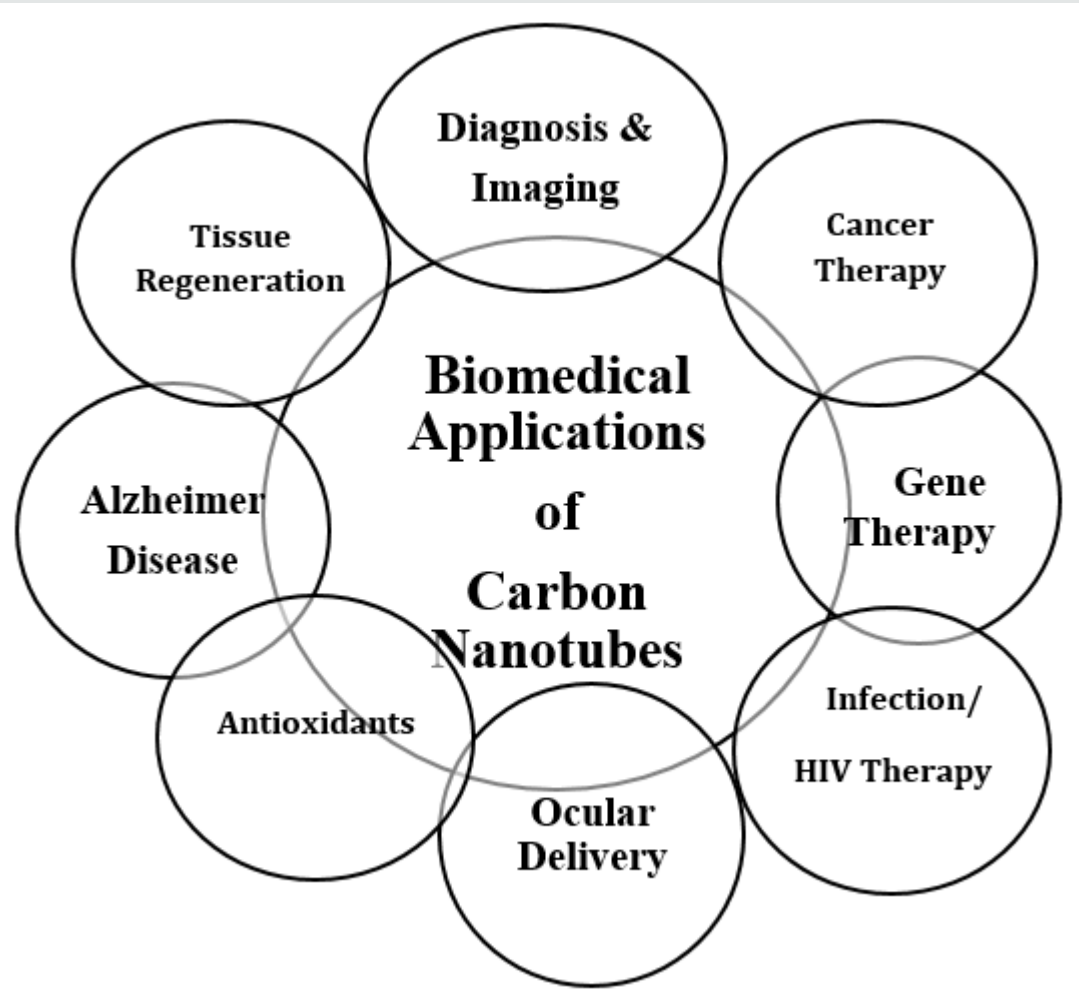

Figure 1: Intrinsic Biomedical Applications of Carbon Nanotubes (CNT). 
I. Diagonsis and Imaging: CNT act as biosensor or Nanorobots, which helps in diagnosis of disease, their progression level and their pathological condition in quick and better way. CNT biosensor are made up by conjugating different biochemicals with CNTs, like in glucuometer biosensor, glucose peroxidase is conjugated with CNTs that is use for the detection of blood sugar level in diabetic patients. Another example is SWCNTs-DNA biosensor that is use of detection of antigen -antibody comlex, which further helps in molecular diagnosis in pathology $[7,8]$. Complex of fluorescent agents and CNTs act as radio-opique agent that is use for the detection of cell and biological system in In-vivo organs [9].

II. Cancer Therapy: Carbon nantubes are effective against Pancreatic Cancer, Brain Cancer, Blood Cancer, Breast Cancer, Colon Cancer, Liver Cancer, Lymph Node, Metastasis, Prostate Cancer by using different anticancer drugs like Paclitaxel, Daunorubicin, Amphotericin B, Carboplatin, siRNA, Doxorubicin, Metal halides, Methotrexate etc. Apart from drug delivery route there are another two methods for cancer therapy using CNTs are immunotherapy and anti-tumor hyperthermia therapy [10].

III. Gene Therapy: CNTs and CNHs are used as vector in genetic engineering due to their cylindrical nature, which wrap the desired DNA and deliver it to target site to cure the genetic disorders by correcting misread or missense gene sequence [7].

IV. Infection/HIV Therapy: CNTs itself have antimicrobial activity by oxidising intracellular glutathione and resulted increase the oxidative stress on microbial cell that cause natural death of pathogen. CNTs also used in number of vaccinations to active immune response by triggering MHC-II, which further promote natural antibody production to stop the infection [11]. HIV( human immunodeficiency virus) that attack the immune response and decline the natural immunity, till date we cannot stop it completely but we can suppress or stop virus multiplication and control the disease .In this case conjugation of CNTs with siRNA that further deliver to T-Cell to stop virus proliferation [12].

V. Ocular Delivery: In case of ocular delivery there are number of challenges to deliver the drug to get adequate response with minimizing risk of infection. So therefore, SWCNTs- $\mathrm{NH}_{3}+$ used as carrier to deliver antigen synthetic vaccination, safely and effectively by avoiding risk of necrosis and tissue degeneration [13].

VI. As Antioxidant: CNTs and CNHs are natural anti-oxidants. They are used in preserving drug molecules in formulation by inhibiting their oxidation. Furthermore, due to this property they are also used in anti-aging cosmetics products that oxidized the skin and stay it healthy and young [7].

\section{Neurodegenerative}

(ND)/Alzheimer

Disease: Graphene sheets, and by extension CNTs, are excellent conductors of electricity, and thus are highly useful in the regeneration of neurons.
Neurons can grow successfully on CNT beds, and modifying the surface with 4-hydroxyonoenal, known to be involved with neuron growth, can improve the neuron length and degree of branching over CNTs [11]. CNTs have many small additional sites that provide high surface area for external modification that's why it is use as carrier to deliver the acetylcholine through blood brain barrier (BBB) and to treat Alzheimer Disease [14-16].

VIII. Tissue/Bone Regenreation: CNTs for the purpose of bone regeneration are being developed, which use negatively charged functional groups with calcium bonded to them. This can provide a scaffold to which hydroxyapatite, the most common inorganic component of bone, can attach. CNTs are very strong, stiff, and flexible which makes them an excellent alternative to the titanium or ceramic bone scaffolds $[17,18]$.

IX. Carbon based nonmaterial by virtue of its therapeutic and diagnostic dual functions have emerged as theranostic nanomedicine. Carbon nanotubes intrinsic medicinal activities along with drug candidates may enhance the effectiveness of drug delivery. Unprecedented growth of patents and publication in last decade has forecasted the future of carbon based drug materials. A precise control for synthesis, purification and tools to increase solubility and further bio-functionality may lead to the development of carbon naotube based formulations. There is a need of clinical investigations for exploring the intrinsic medicinal activities of carbon nanotubes.

\section{References}

1. Kroto HW, Heath JR, O'brien SC, Curl RF, Smalley RE (1985) C 60: buckminsterfullerene. Nature 318: 162-163.

2. Iijima S (1991) Helical microtubules of graphitic carbon. Nature 354: 56-58.

3. Iijima S, Hichihashi T (1993) Single-shell carbon nanotubes of 1-nm diameter. Nature 363: 603-605.

4. Iijima S, Yudasaka M, Yamada R, Bandow S, Suenaga K, et al. (1999) Nanoaggregates of single walled graphitic carbon nano-horns. Chem Phys Lett 309: 163-170.

5. H Wang I, M Chhowalla, Sano N, Jia S, Amaratungal GAJ (2004) Large scale synthesis of single walled carbon nanohorn by submergedarc. Institute of Physics publishing, nanotechnology, pp. 546-550.

6. Dresselhaus MS, Dresselhaus G, Charlier JC, Hernandez E (2004) Electronic, Thermal and mechanical properties of carbon nanotubes. PhysEngSci 362: 2065-2098.

7. Hirlekar R, Yamagar M, Garse H, Mohit Vij (2009) Carbon nanotubes and its applications: a review. Asian Journal of Pharmaceutical and Clinical Research 2: 17-27.

8. Heller A, Feldman B (2008) Electrochemical glucose sensors and their applications in diabetes management. Chem Rev 108: 2482-2505.

9. Star A, Tu E, Niemann J, Gabriel JCP, Joiner CS, et al. (2006) Label-free detection of DNA hybridization using carbon nanotube network fieldeffect transistors. In Proceedings of the National Academy of Sciences USA 103: 921-926.

10. Liu Z, Chen K, Davis C, Sherlock S, Cao Q, et al. (2008) Drug delivery with carbon nanotubes for in vivo cancer treatment. Cancer Res 68: 66526660 . 
11. He H, Pham Huy LA, Dramou P, Deli Xiao, Pengli Zuo, et al. (2013) Carbon nanotubes: applications in pharmacy and medicine. BioMed Research International, pp. 578290.

12. Liu Z, Winters M, Holodniy M, Dai H (2007) siRNA delivery into human T-cells and primary cells with Carbon nanotube transporters. Angewandte Chemie International Edition 46: 2023-2027.

13. Prato M, Kostarelos K, Bianco A (2007) Functionalized carbon nanotubes in drug design and discovery. Accounts Chem Research 41: 60-68.

14. Bokara KK, Kim JY, Lee YI, Yun K, Webster TJ, et al. (2013) Biocompatibility of carbon nanotubes with stem cells to treat CNS injuries. Anatomy \& Cell Biology 46: 85-92.

15. Yang Z, Zhang Y, Yang Y, Sun L, Han D, et al. (2010) Pharmacological and toxicological target organelles and safe use of single-walled carbon nanotubes as drug carriers in treating Alzheimer disease. Nanomed Nanotech Bio and Med 6: 427-441.

16. Caraglia M, De R G, Salzano G, Santini D, Lamberti M, et al. (2012) Nanotech revolution for the anti-cancer drug delivery through bloodbrain barrier. Current Cancer Drug Targets 12: 186-196.

17. MacDonald RA, Laurenzi BF, Viswanathan G, Ajayan PM, Stegemann, JP (2005) Collagen-carbon nanotube composite materials as scaffolds in tissue engineering. J Biomed Mater Res 74: 489-496.

18. Bianco A, Kosteralos K, Partidos CD, Prato M (2005) Biomedical applications of functionalised carbon nanotubes, Chem Commun (camb) 5: 571-577.

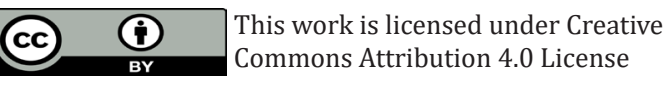

To Submit Your Article Click Here: Submit Article

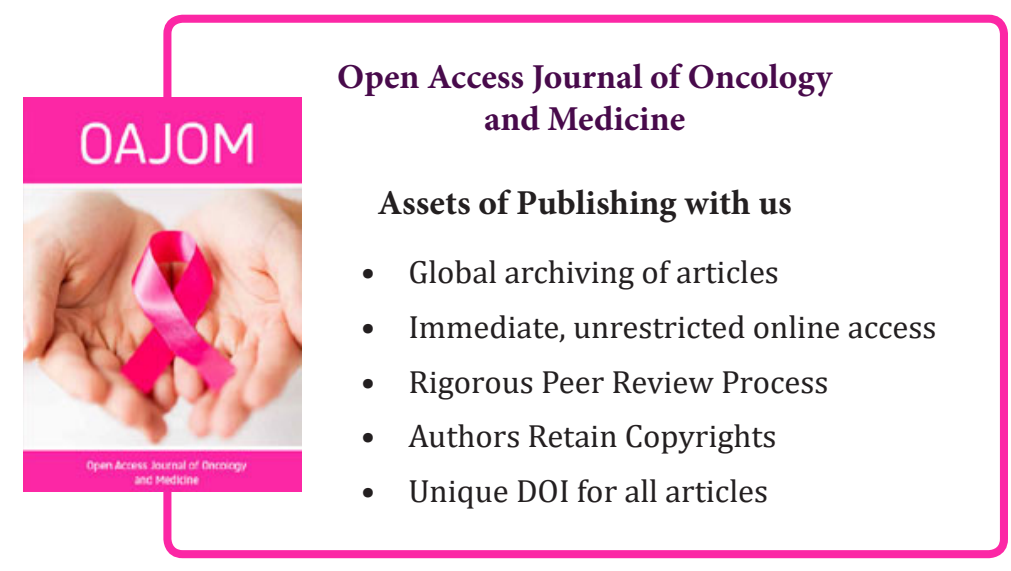

